\title{
Peripheral facial palsy caused by neoplastic meningitis.
}

\section{$\operatorname{AUTHOR}(S)$ :}

Hiraumi, Harukazu; Yamamoto, Norio; Sakamoto, Tatsunori; Ito, Juichi

\section{CITATION:}

Hiraumi, Harukazu ...[et al]. Peripheral facial palsy caused by neoplastic meningitis.. The Laryngoscope 2014, 124(9): 2139-2143

\section{ISSUE DATE:}

2014-05-02

URL:

http://hdl.handle.net/2433/200280

\section{RIGHT:}

This is the peer reviewed version of the following article: Hiraumi, H., Yamamoto, N. Sakamoto, T. and Ito, J. (2014), Peripheral facial palsy caused by neoplastic meningitis. The Laryngoscope, 124: 2139-2143, which has been published in final form at http://dx.doi.org/10.1002/lary.24687. This article may be used for non-commercial purposes in accordance with Wiley Terms and Conditions for Self-Archiving.; この論文は出版社版でありません。引用の際には出版 社版をご確認ご利用ください。;This is not the published version. Please cite only the published version. 
Peripheral facial palsy caused by neoplastic meningitis

\author{
HARUKAZU HIRAUMI, MD, PhD, NORIO YAMAMOTO, MD, PhD, \\ TATSUNORI SAKAMOTO, MD, PhD, JUICHI ITO, MD, PhD
}

Department of Otolaryngology, Head and Neck Surgery, Graduate School of

Medicine, Kyoto University, Kyoto, Japan

Running Title: Facial palsy and neoplastic meningitis

Corresponding author

HARUKAZU HIRAUMI, MD, PhD

Department of Otolaryngology-Head and Neck Surgery

Graduate School of Medicine, Kyoto University

Kawaharacho 54, Shogoin, Sakyo-ku, 606-8507 Kyoto, Japan

Tel: +81-75-751-3346 Fax: +81-75-751-7225

E-mail: hhiraumi@ent.kuhp.kyoto-u.ac.jp

This paper was presented at the Triological Society $116^{\text {th }}$ Annual Meeting at 
COSM, Orlando, Florida, U.S.A., April 10-14, 3013.

This study was supported by a JSPS KAKENHI Grant Number 25462636 and the Japan Health Foundation.

We do not have any financial relationships with the organizations that sponsored this research.

There have been no conflicts of interest in the drafting of this manuscript. 
Peripheral facial palsy caused by neoplastic meningitis

Objective: To describe the clinical presentation of peripheral facial palsy

caused by neoplastic meningitis.

Study design: Retrospective case series.

Methods: Retrospective review, including accompanying symptoms and MRI findings.

Results: Between January and December 2011, 6 patients were diagnosed with peripheral facial palsy caused by neoplastic meningitis. The patient age at presentation ranged from 56 to 77 years. The tumor origins were as follows: malignant lymphoma $(n=3)$, lung cancer $(n=2)$, and kidney cancer $(n=1)$. In 3 patients, sudden sensorineural hearing loss accompanied the facial palsy. Three patients were judged to be tumor free at the onset of the facial palsy. In 2 patients, the malignancy was not diagnosed at the onset of facial palsy and hearing loss. Only one patient was diagnosed as having a tumor at the onset of the facial palsy. On the MRI, a mass lesion was detected in the internal auditory canals of 4 patients, one of whom had a solitary internal auditory canal tumor. In this patient, the diagnosis required 
a histopathological study using a translabyrinthine approach. In the other 2 patients, the facial nerve was enhanced with gadolinium, but it was difficult to differentiate the observed condition from Bell's palsy. In these patients, repeated cytological studies led to the correct diagnoses.

Conclusions: The clinical symptoms and MRI findings of peripheral facial palsy caused by neoplastic meningitis sometimes mimic those of benign facial palsy.

Keywords: leptomeningeal carcinomatosis, carcinomatous meningitis, internal auditory canal metastasis, Bell's palsy

Level of evidence: 4 
Introduction

Peripheral facial palsy is a relatively common disease with diverse origins.

The most frequent causes, Bell's palsy and infectious disease, account for $65-90 \%$ of cases 1,2 . Therefore, peripheral facial palsy is often diagnosed as

Bell's palsy or Ramsay Hunt syndrome when the ear drum and the external auditory canal are normal, the parotid gland tumor is not palpated, and cranial nerve functions are normal except for the facial and auditory nerve. However, we always have to keep it in mind that "All that palsies is not Bell's."3 Peripheral facial palsies caused by tumors account for only $5 \%$ of all facial palsy cases, and most of these tumors are benign, including vestibular schwannomas, parotid tumors, cholesteatomas, and glomus jugulare tumors 2. Although facial palsies caused by malignant tumors are rare, they are clinically important because the prognosis differs greatly from that of the other causative conditions. Malignant tumors may violate the facial nerve anywhere from the parotid gland to the facial nucleus ${ }^{4}$. The most common malignant tumor causing facial palsy is parotid cancer, and the importance of carefully reviewing the parotid gland is well recognized in the assessment of facial palsy ${ }^{5}$. However, other malignant tumors are rarely recognized as a 
cause of facial palsy.

Neoplastic meningitis is a condition in which malignant tumor cells infiltrate into the meninges. Neoplastic meningitis commonly shows tumor growth within the internal auditory canal (IAC) ${ }^{6}$ a and can cause peripheral facial palsy. Although the incidence of neoplastic meningitis has been steadily rising ${ }^{7,8}$, neoplastic meningitis has been underestimated as a cause of facial palsy and few studies have reported about the clinical presentation of this condition.

In this paper, we describe the clinical presentation of peripheral facial palsy caused by neoplastic meningitis.

Materials and methods

Between January and December 2011, 64 patients with peripheral facial palsy presented at Kyoto University Hospital. These patients underwent careful inspection of the auricle, ear canal, tympanic membrane, oral mucosa, and skin of the head and face. All cranial nerves were assessed and thorough neurological work-up were conducted. The parotid gland was examined by ultrasonography. The pure tone audiometry was done for hearing assessment. 
All patients received temporal bone CT for the examination of the temporal bone lesion. Further exploration was conducted in patients with bilateral simultaneous palsy, involvement of multiple cranial nerves, signs of central nervous system lesion ${ }^{9}$, concomitant malignancy, or no sign of recovery 3 months after the onset. MRI with gadolinium enhancement was indicated for these patients. Patients were followed up until they get total recovery or were stable for more than 6 months. Forty-one cases were caused by Bell's palsy, 11 cases were caused by Ramsay Hunt syndrome, 3 cases were caused by surgery, 2 cases were caused by parotid tumors, and 1 case was caused by otitis media. The remaining 6 patients were diagnosed with neoplastic meningitis. The medical records of these patients were retrospectively reviewed to collect the clinical information and the MRI findings. In addition, we reviewed previous studies reported between 2001 and 2011 to assess the clinical and radiological findings of facial palsy caused by neoplastic meningitis.

Results

Case 1 
A 71-year-old male noticed dizziness 3 months before presenting at our institution. One month before presenting, he experienced sudden right sensorineural hearing loss and consulted another hospital. An MRI showed a solitary tumor in the right IAC (Fig. 1), and the patient was referred to our hospital with a diagnosis of vestibular schwannoma. In our department, he presented with mild right facial palsy (House-Brackmann Grade 2). His hearing threshold was $65.0 \mathrm{dBHL}$ on the right and $16.7 \mathrm{dBHL}$ on the left. The patient did not demonstrate any other neurological abnormal findings. Six months prior to presenting, he underwent total resection of renal cell carcinoma (T3N0M0), following which there was no evidence of disease. His facial palsy deteriorated to Grade 4 within 2 weeks. Surgical intervention was conducted via the translabyrinthine approach. The tumor was hemorrhagic and had invaded the facial nerve. The frozen section histology showed that the tumor was metastatic. Bony decompression with partial tumor resection was conducted. After surgery, the facial palsy improved to Grade 2. Despite radiation and chemotherapy, the patient died of disease 4 months post-surgery. 
Case 2

A 76-year-old male developed left facial palsy. Three days prior to the palsy, he noticed left hearing loss. He was diagnosed with small cell lung cancer, and brain metastasis was observed. The facial palsy was Grade 3. His hearing threshold was $55.0 \mathrm{dBHL}$ on the right and $77.5 \mathrm{dBHL}$ on the left. The brain MRI revealed a tumor in the left IAC in addition to disseminated tumors. He was administered steroids and underwent chemotherapy. His facial palsy deteriorated to Grade 6, and hearing was eventually lost in both ears. The patient died of disease 7 months after the onset of the facial palsy.

Case 3

A 76-year-old male developed left facial palsy. He had been treated for malignant lymphoma of the testis 1 year prior and was deemed to be in complete remission. He was diagnosed with Bell's palsy and was administered systemic steroids. Three months later, he developed Grade 3 right facial palsy that was resistant to steroid treatment. He did not complain of hearing loss. The MRI showed enhancement along the facial nerve. Cytological study of cerebrospinal fluid revealed recurrence of the 
lymphoma. The right facial palsy recovered after chemotherapy. The patient died of disease 14 months after the onset of facial palsy.

Case 4

A 60-year-old female developed left facial palsy with ear pain. She had been treated for primary central nervous system lymphoma 8 months prior and was deemed to be in complete remission. She was diagnosed with Ramsay Hunt syndrome and was treated with steroids and antiviral drugs. Fourteen days later, she developed right facial palsy and consulted our hospital. The palsy was Grade 6 on both sides. Pure tone audiometry did not show hearing loss. The patient complained of bilateral severe ear pain but did not show any other abnormal neurological findings. The MRI showed enhancement along the facial nerve (Fig. 2). Repeated cytological study of cerebrospinal fluid revealed recurrence of the lymphoma. She underwent chemo-radiotherapy. The facial palsy recovered to Grade 1 on both sides after the treatment. The patient died of disease 30 months after the palsy.

Case 5 
A 60-year-old female developed right facial palsy. She had no history of malignant tumors. The palsy was Grade 6. Pure tone audiometry was normal. She did not show any other abnormal neurological findings and was diagnosed with Bell's palsy. Two months later, she developed hypoesthesia of the left fingers and mild dementia. The MRI showed multiple tumors within the cranium, including the right IAC (Fig. 3). Systemic exploration was conducted, and the patient was diagnosed with lung cancer. She underwent chemoradiotherapy. She also underwent a static plastic surgery. She is alive with disease 27 months after the onset of facial palsy.

Case 6

A 56-year-old male noticed left hearing loss and dizziness 2 weeks prior to presenting. He was diagnosed with idiopathic sudden sensorineural hearing loss and underwent steroid therapy. Subsequent MRI showed a brain tumor, and the patient was referred to our hospital. When he arrived at our department, he was drowsy. He also had left hemiparesis and Grade 2 right facial palsy. His hearing threshold was $1.7 \mathrm{dBHL}$ on the right and $68.3 \mathrm{dBHL}$ on the left. The following day, his facial palsy deteriorated to Grade 3. After a 
biopsy, the patient was diagnosed with primary central nervous system lymphoma. He underwent chemotherapy. The facial palsy improved temporarily. The patient died of disease 7 months after the palsy.

Between 2001 and 2011, we found 16 published case reports of neoplastic meningitis causing facial palsy. A total of 22 cases, including the 6 cases from our series, were reviewed. The primary tumor site, initial symptoms, and brain MRI findings were summarized in Table 1 10-24. The most frequent accompanying symptom was hearing loss, followed by pain in the head and neck region. Fourteen patients had hearing loss and 5 patients complained of ear or head pain around the time of onset of facial palsy. Brain MRI was performed in 21 cases. Five patients showed neuritis-like or normal brains. In 8 cases, solitary tumors were found in the IAC and the cerebellopontine angle. Only 8 cases showed multiple brain tumors or leptomeningeal enhancement. At the onset of peripheral facial palsy, a malignant tumor was suspected in only 6 cases. Five patients were initially diagnosed with Bell's palsy or neuritis. In 8 cases, benign IAC tumor was suspected. 


\section{Discussion}

In the diagnosis of acute facial palsy, a thorough neurological examination, ear examination, parotid gland palpation, and pure tone audiometry are routinely conducted. Abnormal findings other than facial palsy are indication for imaging. Even with these work-up, the underlying pathology can be overlooked. For example, both CT and MRI may not identify a small parotid gland tumor, especially if it is located in the deep lobe or close to the stylomastoid foramen ${ }^{25}$. In our case series, 3 of 6 patients showed sudden sensorineural hearing loss occurring around the onset of the facial palsy, and 2 patients had concurrent malaise. The patients underwent MRI and IAC tumors with/without intracranial dissemination were found. The other 3 patients had no abnormal findings other than peripheral facial palsy; they were initially diagnosed with Bell's palsy or Ramsay Hunt syndrome. MRI was performed only after the emergence of new neurological symptoms: bilateral facial palsy and hypoesthesia of the left fingers and mild dementia. In 1997, Imamura et al. ${ }^{26}$ reviewed the literature and summarized 9 cases of neoplastic meningitis invading the temporal bone. The authors found that 8 patients showed facial palsy. All 9 patients had hearing loss, which was 
bilateral in 7 cases. In most cases, the initial symptom was hearing loss, and facial palsy developed later. Thus the authors observed that the characteristic symptom of neoplastic meningitis is bilateral hearing loss followed by facial palsy. In recently published case reports, however, the clinical presentations seem different from those reviewed by Imamura et al. 26. Among the 16 published cases reported between 2001 and 2011, 5 patients did not have hearing loss. Bilateral hearing loss was found in only 2 cases. In our series, hearing loss was found in 3 of 6 cases, and only one patient developed bilateral hearing loss, indicating that the clinical presentation of neoplastic meningitis has changed. This change may be partially attributed to early diagnosis of this condition. Goyault et al. reported the MRI findings of 14 patients with neoplastic meningitis involving the IAC 27 . Among the 14 patients, only 5 showed sensorineural hearing loss. In 3 patients with hearing loss, the inner ear was enhanced with gadolinium. The authors speculated that the hearing loss did not occur before the tumor infiltrated the inner ear. Recent improvements in diagnostic tools may have allowed neoplastic meningitis involving the IAC to be diagnosed before it causes hearing loss. 
MRI with gadolinium enhancement is the most useful imaging tool in patients with facial palsy suspected of having neoplastic meningitis $7,8,28$. The most frequent MRI findings are subarachnoid nodules and leptomeningeal enhancement. Brain parenchymal metastases also indicate the neoplastic meningitis 7 . However, MRI sensitivity is limited, particularly in patients with neoplastic meningitis caused by lymphoma and leukemia. The MRI sensitivity is reported to be as low as $29-46 \%$ in patients with hematological malignancies 29,30 . In addition, the positive findings in MRI do not always lead to the correct diagnosis of neoplastic meningitis when the enhancement of the subarachnoid nodule is limited in the IAC. For example, in cases with a solitary IAC lesion, the lesion may be diagnosed as a vestibular schwannoma. In some cases as in our case numbers 3 and 4 , facial nerve enhancement, mimicking the findings of Bell's palsy or Ramsay Hunt syndrome, is observed. Actually, only 8 of the 22 reviewed cases were diagnosed as neoplastic meningitis at the time of the first MRI. In such cases, cytological or histological examination should be considered when the clinical findings suggest neoplastic meningitis. 
Neoplastic meningitis has received little attention as a potential cause of peripheral facial palsy. However, this oversight appears to be changing. Neoplastic meningitis occurs in approximately $5 \%-10 \%$ of all patients with malignant tumors, and the incidence has been steadily rising 7,8 . Despite the high incidence, the clinical importance of neoplastic meningitis has been ignored because it usually occurs in the terminal stage of the malignant tumor. Recent improvements in chemotherapy have enabled long-term survival of patients with systemic metastasis. Because chemotherapeutic agents have poor meningeal penetration, we are more likely to encounter neoplastic meningitis patients with good control of tumor at other sites. To diagnose neoplastic meningitis-derived facial palsy, regular check-ups for neurological symptoms are needed during follow-up.

Conclusions

Neoplastic meningitis can be a cause of peripheral facial palsy in patients with apparently good general health. The clinical symptoms are sometimes nonspecific. The most frequent accompanying symptom is hearing loss, but this symptom is not always present. Careful follow-up is necessary to detect 
delayed abnormal neurological symptoms. Patients with suspected neoplastic meningitis should be subjected to imaging. MRI with gadolinium enhancement is the most useful imaging tool. Nevertheless, the MRI findings may mimic those of Bell's palsy and vestibular schwannoma. In such cases, cytological or histological examination is indicated. 
Acknowledgments

This study was supported by a JSPS KAKENHI Grant Number 25462636 and by a grant from Japan Health Foundation.

We do not have any financial relationships with the organizations that sponsored this research. 
Bibliography

1. Ljostad U, Okstad S, Topstad T, Mygland A, Monstad P. Acute peripheral facial palsy in adults. J Neurol 2005; 252:672-676.

2. Bleicher JN, Hamiel S, Gengler JS, Antimarino J. A survey of facial paralysis: etiology and incidence. Ear Nose Throat J 1996; 75:355-358.

3. Cawthorne T. Bell's Palsies. Ann Otol Rhinol Laryngol 1963; 72:774-779.

4. May M, Schaitkin BM. Tumors involving the facial nerve. In: May M, Schaitkin BM, eds. The facial nerve. New York: Thieme, 2000:393-408.

5. Chan EH, Tan HM, Tan TY. Facial palsy from temporal bone lesions. Ann Acad Med Singapore 2005; 34:322-329.

6. Merchant SN, Nadol JB. Schuknecht's Pathology of the Ear. People's Medical Publishing House, 2010.

7. Le Rhun E, Taillibert S, Chamberlain MC. Carcinomatous meningitis: Leptomeningeal metastases in solid tumors. Surg Neurol Int 2013; 4:S265-288.

8. Van Horn A, Chamberlain MC. Neoplastic meningitis. J Support Oncol 2012; 10:45-53.

9. Schaitkin BM, May M, Klein SR. Office evaluation of the patient with facial palsy: differential diagnosis and prognosis. In: May M, Schaitkin BM, eds. The facial nerve. 
New York: Thieme, 2000:179-212.

10. Marques E, Brandis A, Samii M, Tatagiba M. Late metastasis of breast adenocarcinoma into internal auditory canal and cerebellopontine angle: case report. Arq Neuropsiquiatr 2002; 60:639-642.

11. Martin-Duverneuil N, Hourani R, Tankere F, Auriol M, Lamas G, Chiras J. Intracanalicular facial nerve metastasis presenting as a benign tumor in the internal auditory canal. Eur Radiol 2004; 14:1939-1940.

12. Guilemany JM, Alobid I, Gaston F, Morrello A, Bernal-Sprekelsen M. Cerebellopontine angle and internal auditory canal metastasis from ductal carcinoma of the breast. Acta Otolaryngol 2005; 125:1004-1007.

13. Lee O, Cromwell LD, Weider DJ. Carcinomatous meningitis arising from primary nasopharyngeal carcinoma. Am J Otolaryngol 2005; 26:193-197.

14. Baba S, Matsuda H, Gotoh M, Shimada K, Yokoyama Y, Sakanushi A. A case of meningeal carcinomatosis presenting with the primary symptoms of facial palsy and sensorineural deafness. J Nippon Med Sch 2006; 73:240-243.

15. Schrock A, Laffers W, Bootz F. Solitary metastasis of lung carcinoma to the internal auditory canal. Am J Otolaryngol 2006; 27:214-216.

16. Brackmann DE, Doherty JK. CPA melanoma: diagnosis and management. Otol 
Neurotol 2007; 28:529-537.

17. Chang KH, Song CE, Seo JH, Yeo SW. Solitary metastasis of bronchogenic adenocarcinoma to the internal auditory canal: a case report. J Korean Med Sci $2009 ; 24: 1227-1229$.

18. Favier L, Ladoire L, Guiu Bet al. Carcinomatous Meningitis from Unknown Primary Carcinoma. Case Rep Oncol 2009; 2:177-183.

19. Kariya S, Cureoglu S, Schachern PA, Paparella MM, Nishizaki K. Histopathological temporal bone study of the metastatic rhabdomyosarcoma. Auris Nasus Larynx 2009; $36: 221-223$.

20. Kubo T, Takigawa N, Kiura Ket al. Efficacy of a lumbo-peritoneal shunt for meningeal carcinomatosis refractory to gefitinib treatment. Anticancer Res 2009; 29:2759-2760

21. Chotai NC, Tang PH, Gan BK, Lim CC. Primitive neuroectodermal tumour metastases mimicking neurofibromatosis type 2. Singapore Med J 2010; 51:e98-102.

22. Della Puppa A, Rossetto M, Berti Fet al. Internal auditory canal metastasis. J Neurosurg Sci 2010; 54:159-162.

23. Quadri SA, Sobani ZA, Enam SA, Enam K, Ashraf MS. Primary central nervous system lymphoma causing multiple spinal cord compression and carcinomatous 
meningitis in a 6-year-old: a case report. J Pediatr Hematol Oncol 2011; 33:312-315.

24. Yildiz O, Buyuktas D, Ekiz E, Selcukbiricik F, Papila I, Papila C. Facial nerve palsy: an unusual presenting feature of small cell lung cancer. Case Rep Oncol 2011; $4: 35-38$.

25. Boahene DO, Olsen KD, Driscoll C, Lewis JE, McDonald TJ. Facial nerve paralysis secondary to occult malignant neoplasms. Otolaryngol Head Neck Surg 2004; 130:459-465.

26. Imamura S, Nozawa I, Imamura M, Murakami Y. Clinicopathologic study of leptomeningeal carcinomatosis involving the temporal bone. Ann Otol Rhinol Laryngol 1997; 106:674-679.

27. Goyault G, Kremer S, Martin E, Riehm S, Dietemann JL, Veillon F. Leptomeningeal carcinomatosis and sensorineural hearing loss: correlation of labyrinthine enhancement patterns with symptoms. J Neuroradiol 2009; 36:98-101.

28. Alaani A, Hogg R, Saravanappa N, Irving RM. An analysis of diagnostic delay in unilateral facial paralysis. J Laryngol Otol 2005; 119:184-188.

29. Zeiser R, Burger JA, Bley TA, Windfuhr-Blum M, Schulte-Monting J, Behringer DM. Clinical follow-up indicates differential accuracy of magnetic resonance imaging and immunocytology of the cerebral spinal fluid for the diagnosis of neoplastic 
meningitis - a single centre experience. Br J Haematol 2004; 124:762-768.

30. Pauls S, Fischer AC, Brambs HJ, Fetscher S, Hoche W, Bommer M. Use of magnetic resonance imaging to detect neoplastic meningitis: limited use in leukemia and lymphoma but convincing results in solid tumors. Eur J Radiol 2012; 81:974-978. 
Figure Legends

Figure 1

An axial gadolinium-enhanced T1-weighted MRI from case 1 showing a solitary tumor (arrow head) in the right internal auditory canal. The tumor was irregular within the posterior cranium.

Figure 2

An axial gadolinium-enhanced T1-weighted MRI from case 4 showing a small enhancement in the geniculate ganglion and the fundus of the left internal auditory canal (arrow head). These findings mimicked those of Bell's palsy.

Figure 3

An axial gadolinium-enhanced T1-weighted MRI from case 5 showing a tumor in the right internal auditory canal (arrow head) and the temporal lobe (arrow). Tumor metastases were also detected throughout the brain. 


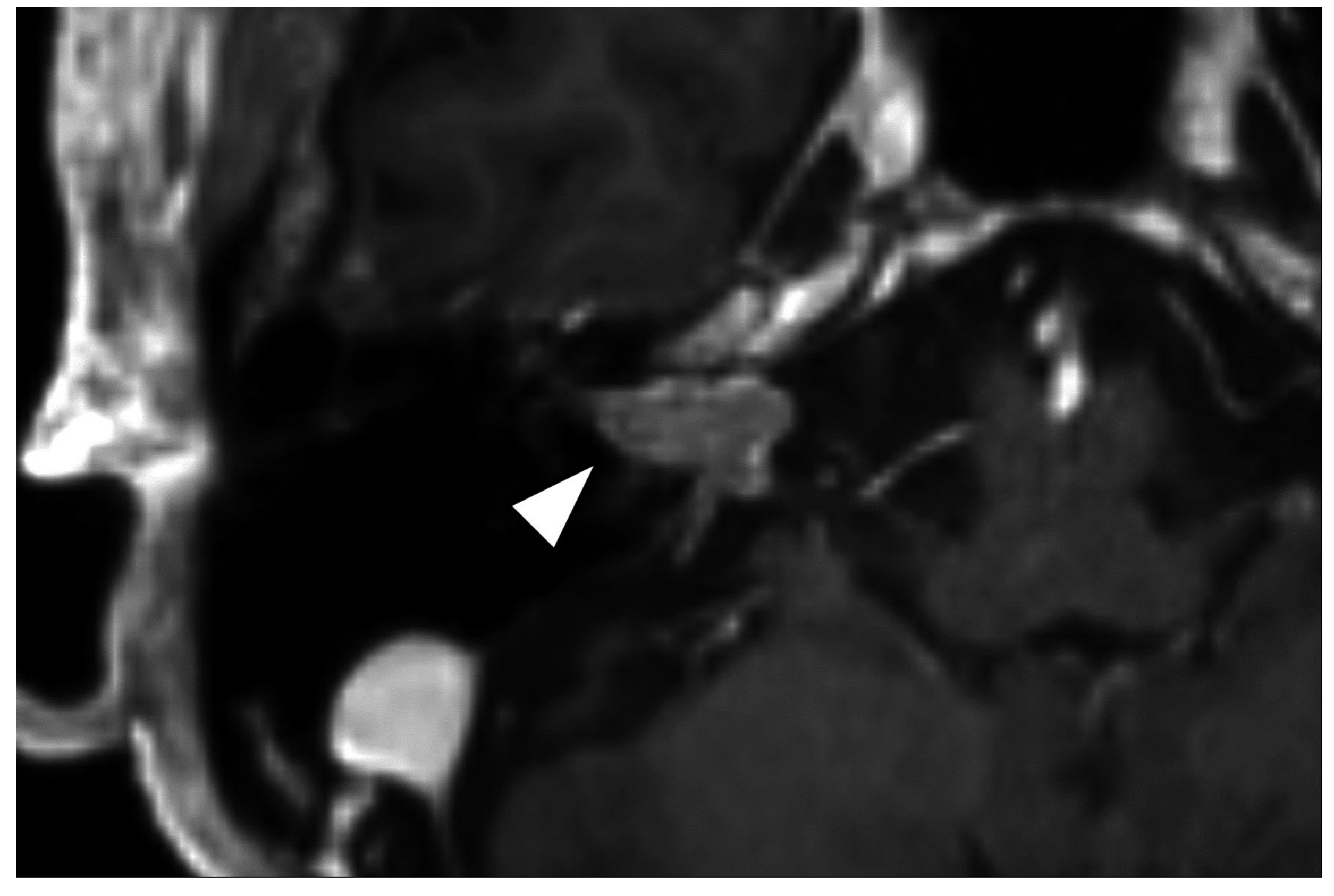

Figure 1 


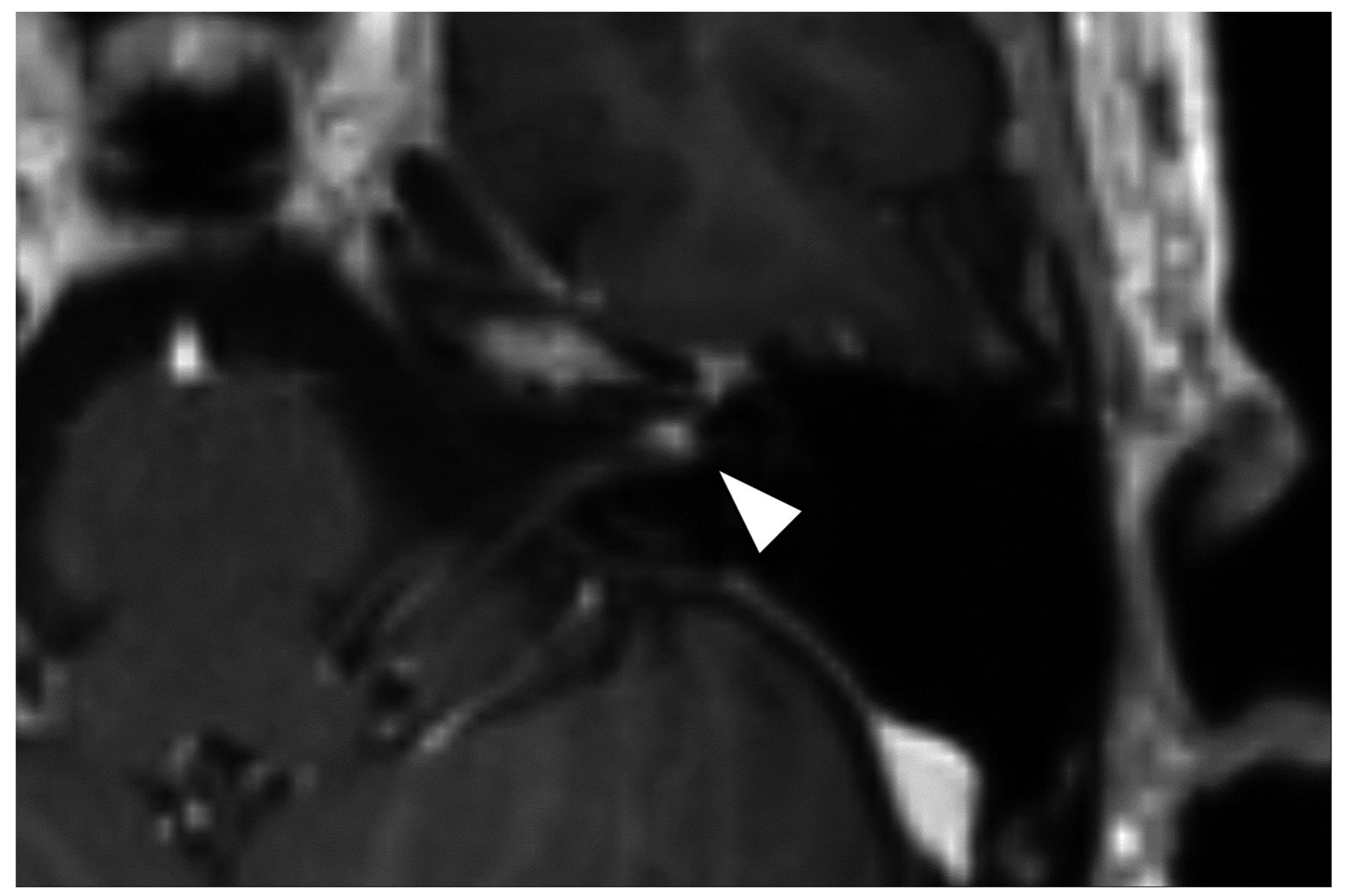

Figure 2 


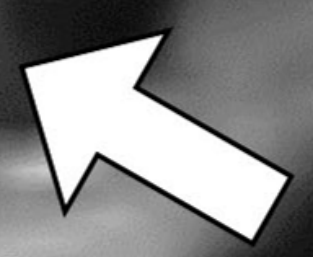

Figure 3 
Table 1

Literature for peripheral facial palsy caused by neoplastic meningitis

\begin{tabular}{|c|c|c|c|c|c|c|}
\hline Author & Primary site & Palsy & Hearing loss & Initial symptoms and findings & Initial diagnosis & Brain MRI \\
\hline Marques et al. (7) & Breast & unilateral & unilateral & & neuritis & Neuritis-like \\
\hline $\begin{array}{l}\text { Martin-Duverneuil et al. } \\
\text { (8) }\end{array}$ & Lung & unilateral & unilateral & & $(-)$ & IAC tumor \\
\hline Guilemany et al. (9) & Breast & unilateral & unilateral & & VS & CPA/IAC tumor \\
\hline Lee et al. (10) & Nasopharynx & unilateral & $(-)^{*}$ & $\begin{array}{l}\text { Anosmia, facial numbness, } \\
\text { facial pain }\end{array}$ & $(-)$ & leptomeningitis \\
\hline Baba et al. (11) & Stomach & unilateral & bilateral & headache & Ramsay Hunt & normal brain \\
\hline Schrock et al. (12) & Lung & unilateral & unilateral & & VS & IAC tumor \\
\hline \multirow[t]{2}{*}{ Brackmann et al. (13) } & MM & unilateral & unilateral & $\begin{array}{l}\text { Facial hypoesthesia, } \\
\text { headache, middle ear mass }\end{array}$ & $\begin{array}{l}\text { facial } \\
\text { schwannoma }\end{array}$ & CPA/IAC tumor \\
\hline & MM & unilateral & unilateral & & malignancy & CPA/IAC tumor \\
\hline Chang et al. (14) & Lung & unilateral & unilateral & & VS & CPA/IAC tumor \\
\hline Favier et al. (15) & Unknown & bilateral & unilateral & & VS & IAC tumor \\
\hline Kariya et al. (16) & RMS & unilateral & bilateral & $\begin{array}{l}\text { Hoarseness, dysphagia, stiff } \\
\text { neck }\end{array}$ & $(-)$ & $(-)$ \\
\hline Kubo et al. (17) & Lung & unilateral & $(-)$ & & metastasis & Multiple tumor* \\
\hline Chotani et al. (18) & PNET & unilateral & $(-)$ & facial hotness, ear pain & $\begin{array}{l}\text { neurofibromatosi } \\
\mathrm{s}\end{array}$ & Multiple tumor \\
\hline Della Puppa et al. (19) & Breast & unilateral & unilateral & & metastasis & Multiple tumor \\
\hline Quadri et al. (20) & $\mathrm{ML}$ & unilateral & $(-)$ & $\begin{array}{l}\text { abducent paresis, neck pain, } \\
\text { limb palsy }\end{array}$ & $\begin{array}{l}\text { neurofibromatosi } \\
\mathrm{s}\end{array}$ & Normal brain \\
\hline Yildiz et al. (21) & Lung & unilateral & $(-)$ & facial numbness, dysphonia, & metastasis & Multiple tumor \\
\hline
\end{tabular}




\begin{tabular}{|c|c|c|c|c|c|c|}
\hline & & & & $\begin{array}{l}\text { weight loss, } \\
\text { lymphadenopathy }\end{array}$ & & \\
\hline \multirow[t]{6}{*}{ Present study } & Kidney & unilateral & unilateral & & VS & $\mathrm{CPA} / \mathrm{IAC}$ tumor \\
\hline & Lung & unilateral & bilateral & malaise & metastasis & Multiple tumor \\
\hline & ML & bilateral & $(-)$ & & Bell's palsy & Neuritis-like \\
\hline & ML & bilateral & $(-)$ & ear pain & Ramsay Hunt & Neuritis-like \\
\hline & Lung & unilateral & $(-)$ & & Bell's palsy & Multiple tumor \\
\hline & $\mathrm{ML}$ & unilateral & unilateral & malaise & malignancy & Multiple tumor \\
\hline
\end{tabular}

Abbreviations: MM: malignant melanoma, RMS: rhabdomyosarcoma, PNET: primitive neuroectodermal tumour, ML: malignant lymphoma, VS: vestibular schwannoma, CPA: cerebellopontine angle, IAC: internal auditory canal

*: bilateral hearing loss occurred at the terminal stage 